\title{
Semiconductor Type Dependent Comparison of Electrical Characteristics of Pt/InP Structures Fabricated by Magnetron Sputtering Technique in the Range of $20-400 \mathrm{~K}$
}

\author{
H. Korkut*
}

(Received 18 December 2012; Accepted 7 March 2013; published online 10 March 2013)

\begin{abstract}
The paper describes how electrical properties of Pt/InP Schottky diode were affected by semiconductor type. We fabricated Pt/p-InP and Pt/n-InP Schottky diodes and measured electrical characteristics from $20 \mathrm{~K}$ to $400 \mathrm{~K}$. Thicknesses of less than $30 \mathrm{~nm}$ of platinum were deposited on the two types of indium phosphide substrates using magnetron sputtering technique after the creation of $\mathrm{Zn}-\mathrm{Au}$ ohmic back contact. We discussed basic diode parameters of idealiy factors, barrier heights and serries resistances of the two type of contacts. Additionly, unusual temperature characteristics of the the diodes were highlighted. These results were evaluated in terms of semiconductor type comparision of Pt/InP Schottky structures.
\end{abstract}

Keywords: Pt/p-InP; Pt/n-InP; Magnetron Sputtering; I-V-T characteristics

Citation: H. Korkut, "Semiconductor Type Dependent Comparison of Electrical Characteristics of Pt/InP Structures Fabricated by Magnetron Sputtering Technique in the Range of 20-400 K", Nano-Micro Lett. 5(1), 34-39 (2013). http://dx.doi.org/10.3786/nml.v5i1.p34-39

\section{Introduction}

The preferred material and technique is mostly effective in the forming of semiconductor devices. InP is an extremely suited substrate since high electron mobility and high speed performance. Platinum is also used in several areas as a gate contact metal in most of devices successfully $[1,2]$. Magnetron sputtering technique is generally used for controlling the thickness distribution and obtaining high rate of uniform surfaces.

It is of great value to form Schottky diodes that have high barrier heights and good thermal stability in the realization of getting better performance. To achieve fabricating such a diode and obtaining the desired characteristics, it is very important to be careful in all stages from selecting material type, using appropriate technique to physical and chemical cleaning and measurement processes. The successful experimental results in different temperature conditions using platinum and InP separately were published in the litterature. Therefore we assess such an option for the material selection. We emphasized the effects of semiconductor type on electrical characteristics in given temperature conditions. Semiconductor type dependent investigations have been done by various researchers. For instance, Yıldız et al. investigated electrical characteristics of $\mathrm{Au} / \mathrm{SnO}_{2} / \mathrm{n}-\mathrm{Si}$ and $\mathrm{Al} / \mathrm{SnO}_{2} / \mathrm{p}-\mathrm{Si}$ Schottky contacts at 200 and 295 K [3]. Siad et al studied series resistance and diode parameter differences between $\mathrm{Al} / \mathrm{n}-\mathrm{Si}$ and $\mathrm{Al} / \mathrm{p}-\mathrm{Si}$ Schottky contacts [4]. Akkılıç et al., determined correlation between barrier heights and ideality factors of $\mathrm{Cd} / \mathrm{n}-\mathrm{Si}$ and $\mathrm{Cd} / \mathrm{p}$-Si Schottky barrier diodes [5]. Arslan et al. published electrical characteristics of $\mathrm{Pt} / \mathrm{p}$-InGaN and $\mathrm{Pt} / \mathrm{n}-\mathrm{InGaN}$ Schottky barriers in a wide temperature range [6].

Department of Physics, Science and Art Faculty, Ağrı Ibrahim Çeçen University, Ağrı, TURKEY

*Corresponding author. E-mail: mhtrvz@gmail.com 


\section{Experimental Section}

In this study, cleaned and polished p-InP and n-InP wafers with respectively $4.8 \times 10^{17} \mathrm{~cm}^{-3}$ and $2.5 \times 10^{15}$ $\mathrm{cm}^{-3}$ carrier concentration and (100) orientation were used. In order to remove undesirable impurities and surface damage layer, wafers were dipped in $5 \mathrm{H}_{2} \mathrm{SO}_{4}$ $+\mathrm{H}_{2} \mathrm{O}_{2}+\mathrm{H}_{2} \mathrm{O}$ solution for 1.0 min. After $\mathrm{H}_{2} \mathrm{O}+$ $\mathrm{HCl}$ solution cleaning process, wafers were cleaned in 18 $\mathrm{M} \Omega$ de-ionized water. High purity nitrogen was used in drying periods. Ohmic contacts were formed by thermal evaporating of $\mathrm{Zn}-\mathrm{Au}$ alloy on $\mathrm{p}-\mathrm{InP}$ and $\mathrm{n}$-InP under $10^{-6}$ Torr pressure in a vacuum chamber. The p-InP and n-InP were annealed respectively at $350^{\circ} \mathrm{C}$ and $300^{\circ} \mathrm{C}$ for $3 \mathrm{~min}$ in flowing $\mathrm{N}_{2}$ to form low resistance ohmic contacts in a quartz tube furnace. DC magnetron sputtering technique was used to form 1.5 $\mathrm{mm}$ diameter circular platinum dots in the other face of $\mathrm{p}-\mathrm{InP}$ and $\mathrm{n}-\mathrm{InP}$ wafers. Platinum thicknesses were about less than $30 \mathrm{~nm}$ as schematically shown in Fig. 1. In fabrication process, while diodes were forming, they were taken under identical conditions to minimize fabrication induced differences. In this context, the main electrical parameters of the diode depending on the semiconductor type will be examined from $20 \mathrm{~K}$ to 400 K. $I-V$ measurements were taken under dark conditions by a Keithley 487 Picoammeter/Voltage Source. We can see the basic measurement system schmatically in Fig. 2. Temperature was controlled by a Leybold Heraeus closed-cycle helium cryostat enables to measure in the 10-340 K temperature range. A Windaus MD850 electronic thermometer was used for reading temperature. Electronic thermometer sensitivity was better than $0.1 \mathrm{~K}$.

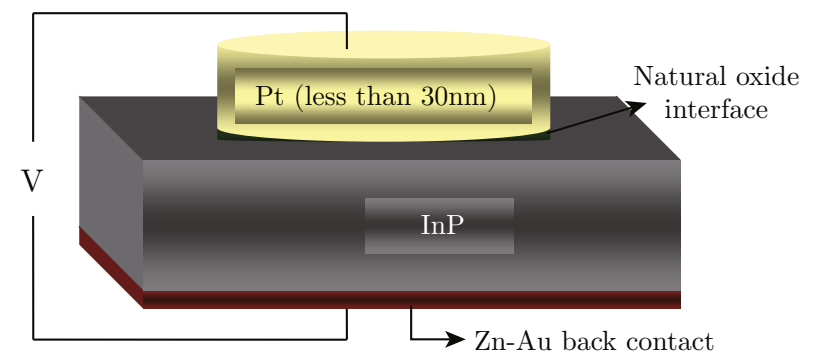

Fig. 1 Schematic diagram of layers of $\mathrm{Pt} / \mathrm{InP} / \mathrm{Zn}-\mathrm{Au}$ Schottky contact.

\section{Results and discussion}

Fabrication technique is one of the basic parameters for getting better device quality. We used magnetron sputtering technique in platinum Schottky metal coating process. Figure 2 shows a basic diagram of a coating process using magnetron sputtering technique. This technique permits controlling the thickness distribution and getting high rate of uniform surfaces. So, we can obtain stable contacts. One of the ways of testing contact quality is measuring electrical characteristics.

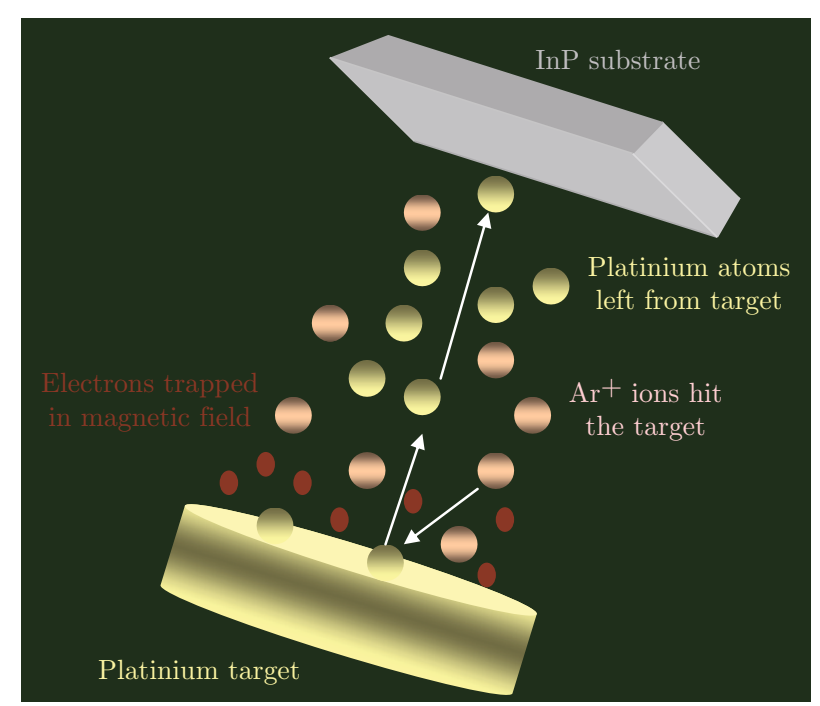

Fig. 2 Schematic diagram of platinum coating on InP substrate by magnetron sputtering technique.

Electrical performance of metal-semiconductor contacts are affected by operation temperatures and properties of preferred semiconductor type. Figure 3 displays current voltage characteristics and basic differences between the two types of Schottky diodes depending on temperatures from $20 \mathrm{~K}$ to $400 \mathrm{~K}$. Temperature stability of various layered electronic structures containing platinum was emphasized in many studies [1]. Pt/p-InP Schottky contact had high quality rectifying behaviour in all temperature conditions. Reverse saturation currents were changed from about $10^{-9} \mathrm{~A}$ to $10^{-6}$ A. Ellipse 1 (E1) explains reverse current features of $\mathrm{Pt} / \mathrm{p}$-InP Schottky contacts in low temperature region. $I_{0}$ minimum currents in negative bias region were changed from about $10^{-14} \mathrm{~A}$ to $10^{-11} \mathrm{~A}$ in temperature range of 200-300 K. Reverse currents behaviour of $\mathrm{Pt} / \mathrm{p}$-InP Schottky diode is very extraordinary as seen in Ellipse (E1). The real reason of this interesting behaviour has not been explained in details. But this fluctuation is mainly attributed to dipole relaxations or reversed carriers passing from the depletion layer to electrode region [7]. The p-type contact reverse currents increase with increasing temperature from just about $10^{-9} \mathrm{~A}$ to $10^{-6} \mathrm{~A}$ in respectively from $20 \mathrm{~K}$ to $400 \mathrm{~K} . \mathrm{Pt} / \mathrm{p}-\mathrm{InP}$ Schottky diode reverse currents have minimums in zero bias in 300-400 K. High performance rectifying capacity of $\mathrm{Pt} / \mathrm{p}$-InP in all temperatures can be seen in Fig. 3 explicitly. In all temperatures forward currents, coming up to approximately $0.5 \mathrm{~A}$, were seen very rarely in litterature. In forward bias, low temperatures induced coincided current voltage characteristics in consecutive temperatures. This result can be attributed to very low series resistance (nano and micro 
ohm) approach of Chand and Bala [8]. Such an intersecting characteristics have not seen in literature up to now in such wide and low temperatures experimentally before. Thus, theoretical approach of Chand and Bala was experimentally verified by this paper. This issue will be discussed again in the course of the results of Norde calculations. In the high temperature region, p-InP based platinum Schottky diode currents were increased with increasing temperatures. In the low temperature region, very low effective barrier height regions were dominant.

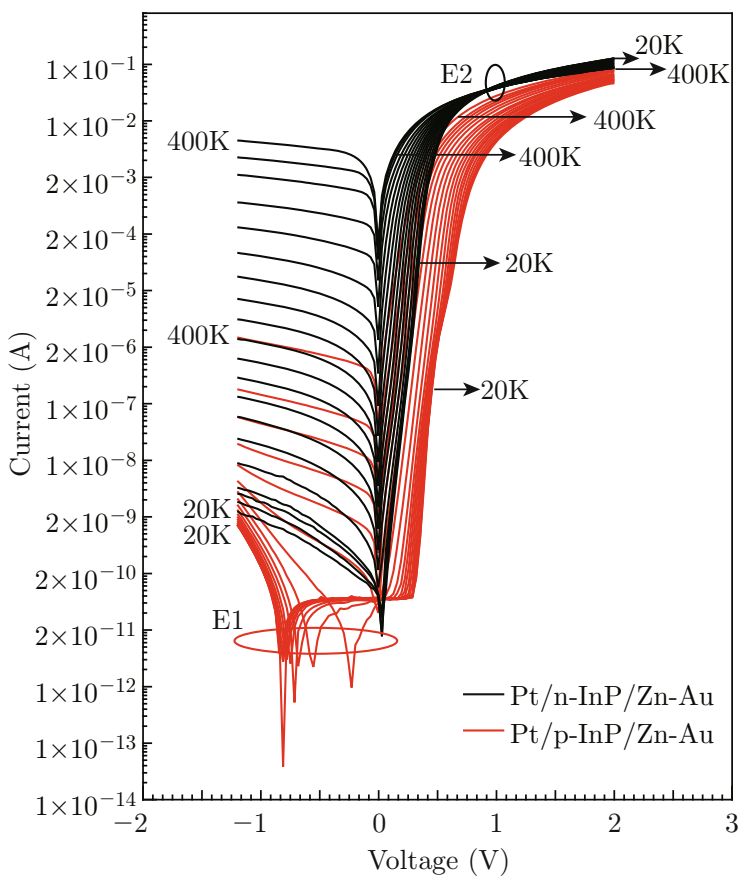

Fig. 3 I-V-T characteristics of $\mathrm{p}$ and n-type InP based platinum Schottky contacts.

Reverse currents of $\mathrm{Pt} / \mathrm{n}$-InP varies as seen in literature clasically. Reverse currents of $\mathrm{Pt} / \mathrm{n}$-InP increase with increasing temperature from about $10^{-9} \mathrm{~A}$ to $10^{-2}$ $\mathrm{A}$ in $20 \mathrm{~K}$ to $400 \mathrm{~K}$ as can be seen in Fig. 3. High performance rectfying capacity of $\mathrm{Pt} / \mathrm{n}$-InP in all temperatures can be seen in Fig. 3 explicitly similar to Pt/pInP. In all temperatures forward currents pass to approximately $0.5 \mathrm{~A}$ values very rarely seen in litterature. Coincided current-voltage characteristics as seen p-type contact in low temperature region were attributed to very low series resistance approach of Chand and Bala [8]. In forward bias region of $\mathrm{Pt} / \mathrm{n}$-InP, Ellipse 2 (E2) explains that currents were increased with decreasing temperature after a cross point. This unussual result obeys series resistance approach suggested by Oswald and Horwath [9]. They simulated current-voltage characteristics and found temperature independent effects after a cross point. They also explained the result as: "The charge carrier scattering in the depletion region is more effective for the purpose of explanation about current flow mechanism for the lower voltages than the cross-point voltage. Thereby, charge scattering limits current in the quasi-neutral portion of the semiconductor in high voltage region". This simulated interesting cross point behaviour of Schottky contacts was proved in this paper by experimentaly current-voltage characteristics of $\mathrm{Pt} / \mathrm{n}-\mathrm{InP}$.

$I-V$ characteristics were investigated by thermionic emission (TE) current equation. The TE equation at forward-bias $(V \geq 3 \mathrm{kT})$ can be given as:

$$
I=I_{0}\left[\exp \left(\frac{e\left(V-I R_{s}\right)}{n k T}\right)\right]
$$

where $I_{0}$ is saturation current and it can be defined as:

$$
I_{0}=A A^{*} T^{2} \exp \left(\frac{-e \Phi_{b}}{k T}\right)
$$

where $A$ is diode area, $A^{*}$ is the effective Richardson constants are respectively $60 \mathrm{~A} \cdot \mathrm{cm}^{-2} \cdot \mathrm{K}^{-2}$ and 9.8 $\mathrm{A} \cdot \mathrm{cm}^{-2} \cdot \mathrm{K}^{-2}$ for p-type InP and n-type InP. $T$ is temperature in Kelvin, $k$ is Boltzmann constant and $e$ is electronic charge and $\Phi_{b}$ is the zero bias barrier height $(\mathrm{BH})$. We can write equations for ideality factor and barrier height as follows:

$$
\begin{aligned}
& n=\frac{e}{k T} \frac{d V}{d(\ln I)} \\
& e \Phi_{b}=k T \ln \left(\frac{A A^{*} T^{2}}{I_{0}}\right)
\end{aligned}
$$

Figure 4 shows ideality factors $(n)$ and barrier heights $\left(\Phi_{b}\right)$ depending on given temperatures. Ideality factors were larger than unity for both diodes in all the temperatures. Ideality factors of $\mathrm{Pt} / \mathrm{n}-\mathrm{InP}$ were smaller than Pt/p-InP Schottky diode in 20-220 K. The $n$ values of both diodes were approximately same in 240 $400 \mathrm{~K}$. Similar barier heights were seen in 20-60 K for both contacts. Barrier height differences between two diodes were increased with increasing temperature in range of 80-240 K. After $260 \mathrm{~K}$ barrier height difference was remained approximately firm. Generally, high barrier height explains a high quality contact performance. High barrier heights of $\mathrm{Pt} / \mathrm{p}-\mathrm{InP} / \mathrm{Zn}$-Au Schottky diode are mostly attracted attention. Barrier heights were increased with increasing temperature from $20 \mathrm{~K}$ to $240 \mathrm{~K}$ as can be seen in Fig. 4. This effect means that inhomogeneous barrier height distributions were fastly changed in the effect of temperature differences for each temperature. Approximately unchanged barrier heights show us barrier height distribution was not changed significantly depending on increasing temperature. 


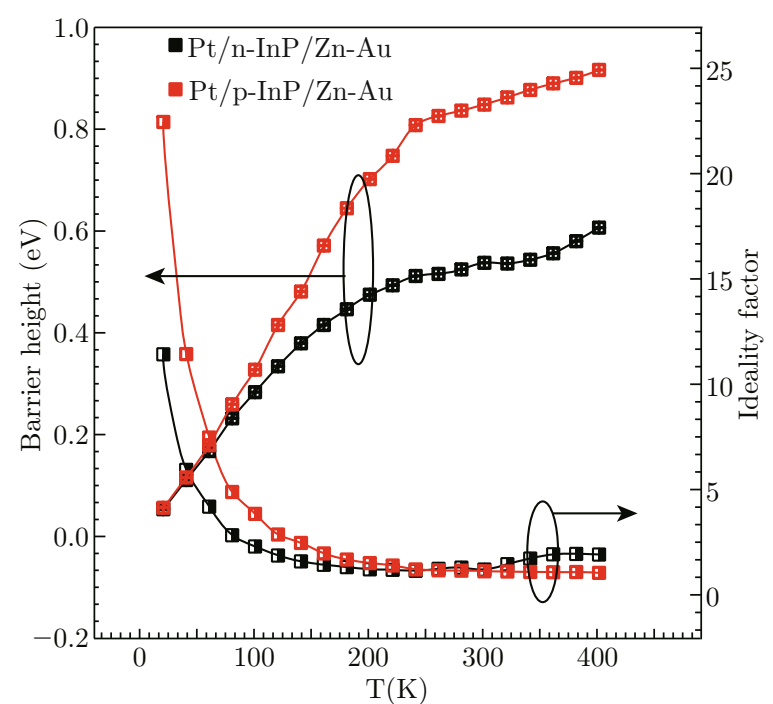

Fig. 4 Temperature dependent ideality factors and barrier heights of $\mathrm{Pt} / \mathrm{p}-\mathrm{InP}$ and $\mathrm{Pt} / \mathrm{n}-\mathrm{InP}$ Schottky diodes.

Linear correlation between ideality factors and barrier heights was verified in most of studies. Figure 5 shows linear and nonlinear portions of ideality factorbarrier height plot. Linear relationship between $n$ and $\Phi_{b}$ were seen only $140-400 \mathrm{~K}$ and $100-400 \mathrm{~K}$ for respectively $\mathrm{Pt} / \mathrm{p}-\mathrm{InP}$ and $\mathrm{Pt} / \mathrm{n}-\mathrm{InP}$ Schottky contacts. Homogeneous barrier heights of $\mathrm{Pt} / \mathrm{p}-\mathrm{InP}$ and $\mathrm{Pt} / \mathrm{n}-\mathrm{InP}$ are respectively $0.891 \mathrm{eV}$ and $0.568 \mathrm{eV}$ in given linear regions. In very low temperatures, nonlinearity is dominant. Nonlinearity behaviour in ideality factor-barrier height is very interesting. Namely, decreases in ideality factors were faster than decreases in barrier heights in the effect of low temperature conditions. So, homogeneous barrier height cannot be calculated from linear relationsip between $n$ and $\Phi_{b}$ for very low temperatures. We can see linearity in BH- $n$ plot in high temperature ranges for both type of diodes. Linear relationship

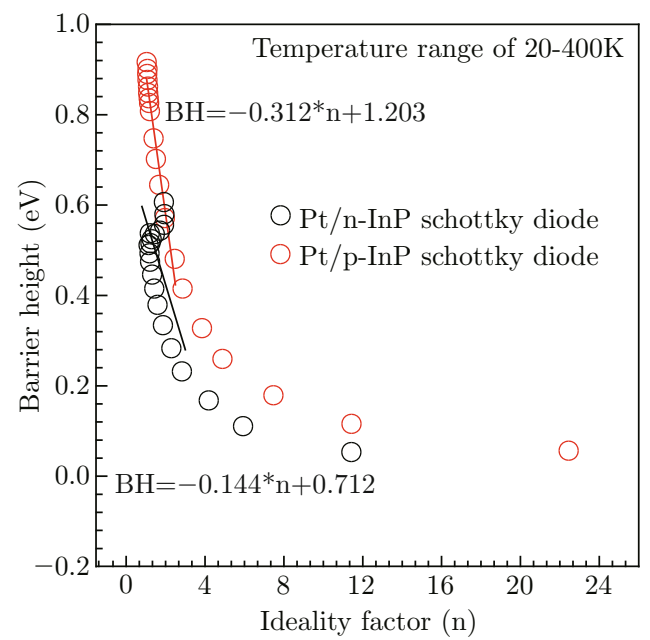

Fig. 5 Ideality factor-barrier hight plots of $\mathrm{Pt} / \mathrm{p}-\mathrm{InP}$ and $\mathrm{Pt} / \mathrm{n}-\mathrm{InP}$ Schottky diodes. between barrier height and $n$ is attributed to inhomogeneous interfaces and barrier heights. But we cannot say the low temperature region has not uniform interface directly. Perhaps, because of sharp changes in consecutive slopes of the linear regions, linear regions can be brought in a curve similar to the parabola in low temperature regions. This result can be explained by temperature independent inhomogeneities of barrier heights. Very low temperature applications of Schottky diodes are not fully understood due to the experimental difficulties. Investigations under $80 \mathrm{~K}$ are very little to enhance a large perspective for a deep explanation of nature of Schottky contacts under this temperature.

Norde proposed a model as follows for series resistance calculations $[10]$ :

$$
F(V)=\frac{V}{\gamma}-\frac{k T}{q} \ln \left(\frac{I(V)}{A A^{*} T^{2}}\right)
$$

where $\gamma$ is an dimensionless integer greater than ideality factor. $I(V)$ shows current values depending on applied bias obtained from $I-V-T$ measurement results. Norde plot is seen in Fig. 6. $R_{S}$ is series resistance and calculated from Eq. 6.

$$
R_{S}=\frac{k T(\gamma-n)}{q I}
$$

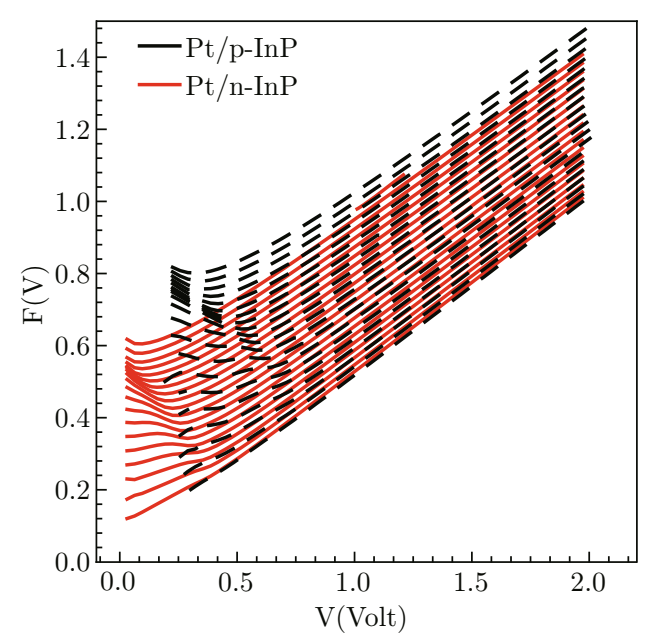

Fig. 6 Norde plots of $\mathrm{Pt} / \mathrm{n}-\mathrm{InP}$ and $\mathrm{Pt} / \mathrm{p}-\mathrm{InP}$ Schottky contacts

Series resistances were seen in Table 1. Mclean explained Norde plot as: function approaches a line with a gradient of $+1 / 2$ if there is only one series resistance [11]. Therefore, two types of $\mathrm{Pt} / \mathrm{InP}$ contacts have unique series resistances at low temperatures in accordance with the approach of Chand and Bala as can be seen in Fig. 6 [8]. The $+1 / 2$ gradient of lines can be seen clearly in Fig. 6 from about $20 \mathrm{~K}$ to $140 \mathrm{~K}$. Norde curves tend from parabolas to linear plots after a critic temperature in high temperature range for both types of contacts as a result of series resistance values. Figure 6 and Table 1 show us relationship between linearity in 
Norde plots and only one series resistance approach of Norde clearly. For respectively $\mathrm{Pt} / \mathrm{n}-\mathrm{InP}$ and $\mathrm{Pt} / \mathrm{p}$-InP diode 20-100 K and 20-140 K temperature regions were seen as one series resistance regions. Norde functions did not have explicit minimums in these regions. This result is compatible with the overlapping $I-V$ curves in low temperatures and very low series resistance approach of Chand and Bala in a perfect way as can be seen in Fig. 3 [8]. Series resistances of both types of contacts depending on temperature were seen in Table 1 .

Table 1 Series Resistances of $\mathrm{Pt} / \mathrm{p}-\mathrm{InP}$ and $\mathrm{Pt} / \mathrm{n}-$ InP Schottky diodes

\begin{tabular}{ccc}
\hline T $(\mathrm{K})$ & Series Resistances & Series Resistances \\
& $\left(\mathrm{R}_{S}, \Omega\right) \mathrm{Pt} / \mathrm{n}$-InP & $\left(\mathrm{R}_{S}, \Omega\right) \mathrm{Pt} / \mathrm{p}-\mathrm{InP}$ \\
\hline 20 & only one series resistance & only one series resistance \\
40 & only one series resistance & only one series resistance \\
60 & only one series resistance & only one series resistance \\
80 & only one series resistance & only one series resistance \\
100 & only one series resistance & only one series resistance \\
120 & 18.34 & only one series resistance \\
140 & 21.22 & only one series resistance \\
160 & 15.77 & 12.67 \\
180 & 29.95 & 15.00 \\
200 & 20.50 & 26.84 \\
220 & 29.68 & 35.33 \\
240 & 23.23 & 42.44 \\
260 & 22.42 & 41.14 \\
280 & 24.53 & 38.03 \\
300 & 21.36 & 19.97 \\
320 & 12.55 & 22.33 \\
340 & 7.27 & 24.63 \\
360 & 1.40 & 18.41 \\
380 & 0.88 & \\
400 & 1.14 & \\
\hline & & \\
\hline
\end{tabular}

\section{Conclusion}

We fabricated Pt Schottky diodes based on $\mathrm{n}$ and p-types of InP semiconductor substrates by magnetron sputtering technique and compared their electrical performance. The stable temperature dependent electrical characteristics showed both two type of DC magnetron sputtered contacts showed excellent performance. The theoritical approaches of Chand and Bala and Oswald and Horwath were proved experimentally by the characteristics of p-type and n-type InP Schottky contact characteristics $[8,10]$. This result is supported by Norde calculations. Barrier heights and ideality factors graph show an interesting unexpected nonlinear behaviour in low temperature region. $\mathrm{Pt} / \mathrm{n}$ and $\mathrm{p}$-type InP Schot- tky diodes demonstrated high rate of electrical response from $20 \mathrm{~K}$ to $400 \mathrm{~K}$.

\section{Acknowledgements}

Authors wish to thank to Ağrı İbrahim Çeçen University BAP because of platinum material support (BAPF07) and also wish to thank to Erzurum Atatürk University for facilities in laboratory research processes. Furthermore, authors wish to thank to Prof. Dr. Abdülmecit Türüt, Dr. Kadir Ejderha and Atakan Akbay for their valuable efforts.

\section{References}

[1] A. Akbay, H. Korkut, K. Ejderha, T. Korkut and A. Türüt, "Responses of Pt/n-InP Schottky diode to electron irradiation in different temperature conditions", J. Radioanal. Nucl. Chem. 289(1), 145-148 (2011). http://dx.doi.org/10.1007/s10967-011-1041-y

[2] P. Veeramani, M. Haris and S. M. Babu, "Investigation of $\mathrm{CdTe}_{\mathrm{x}}$ and $\mathrm{Cd}_{1-\mathrm{x}} \mathrm{Zn}_{\mathrm{x}}$ Te Schottky barrier diode structure based $\gamma$-ray detectors", Mater. Manufact. Proc, 22(3), 375-378 (2007). http://dx.doi.org/10. 1080/10426910701190873

[3] D. E. Yıldız, Ş. Altındal, Z. Tekeli and M. Özer, "The effects of surface states and series resistance on the performance of $\mathrm{Au} / \mathrm{SnO}_{2} / \mathrm{n}-\mathrm{Si}$ and $\mathrm{Al} / \mathrm{SnO}_{2} / \mathrm{p}-\mathrm{Si}$ (MIS) Schottky barrier diodes", Mat. Sci. Semicon. Proc. 13(1), 34-40 (2010). http://dx.doi.org/10.1016/j. mssp. 2010.02.004

[4] M. Siad, A. Keffous, S. Mamma, Y. Belkacem and H. Menari, "Correlation between series resistance and parameters of $\mathrm{Al} / \mathrm{n}-\mathrm{Si}$ and $\mathrm{Al} / \mathrm{p}-\mathrm{Si}$ Schottky barrier diodes", Appl. Surf. Sci. 236(1-4), 366-376 (2004). http://dx.doi.org/10.1016/j.apsusc.2004.05.009

[5] K. Akkiliç, A. Türüt, G. Çankaya and T. Kiliçoğlu, "Correlation between barrier heights and ideality factors of $\mathrm{Cd} / \mathrm{n}-\mathrm{Si}$ and $\mathrm{Cd} / \mathrm{p}-\mathrm{Si}$ Schottky barrier diodes" Solid State Commun. 125(10), 551-556 (2003). http://dx.doi.org/10.1016/ S0038-1098(02) 00829-3

[6] E. Arslan, H. Çakmak and E. Özbay, "Forward tunneling current in Pt/p-InGaN and Pt/n-InGaN Schottky barriers in a wide temperature range" Microelectron. Eng. 100, 51-56 (2012). http://dx.doi.org/10.1016/ j.mee. 2012.07.103

[7] K. Kaneto and W. Takashima, "Fabrication and characteristics of Schottky diodes based on regioregular poly(3-hexylthiophene)/Al junction", Curr. Appl. Phys. 1(4-5), 355-361 (2001). http://dx.doi.org/10. 1016/S1567-1739(01)00035-9

[8] S. Chand and S. Bala, "Analysis of current-voltage characteristics of inhomogeneous Schottky diodes at low temperatures", Appl. Surf. Sci. 252(2), 358363 (2005). http://dx.doi.org/10.1016/j.apsusc. 2005.01 .009 
[9] J. Osvald and Zs. Horvath, "Theoretical study of the temperature dependence of electrical characteristics of Schottky diodes with an inverse near-surface layer", J. Appl. Surf. Sci. 234(1-4), 349-354 (2004). http://dx . doi.org/10.1016/j . apsusc. 2004.05 .046

[10] H. Norde, "A modified forward I-V plot for Schot- tky diodes with high series resistance", J. Appl. Phys. 50, 5052-5053 (1979). http://dx.doi.org/10.1063/ 1. 325607

[11] A. B. Mcleon, "Limitations to the Norde I-V plot", Semicond. Sci. Technol. 1, 177-179 (1986). http://dx. doi.org/10.1088/0268-1242/1/3/003 